\title{
Research on the Insulation Monitoring Devices for DC Power System Based on the Detection Technology of DC Bus to Grounding Capacitance
}

\author{
Zhi-jun LUO ${ }^{1, a}$, Xiao-dan REN ${ }^{1, b}$, Hao YANG ${ }^{2}$, Gang-lin CAI ${ }^{2}$, Chu QING ${ }^{2}$, \\ Yan-ling LUO ${ }^{2}$
}

\author{
${ }^{1}$ XJ Power CO.,LTD., State Grid Corporation of China, Xuchang 461000,Henan,China \\ ${ }^{2}$ Chengdu Chengdian Electic Power Engineering Design CO.,LTD., Chengdou 610000, \\ Sichuan, China
}

aluozhijunxudy@126.com, ${ }^{b}$ renxiaodandy@126.com, byin-1-qiang@163.com

\begin{abstract}
Keywords: insulation monitoring devices; grounding capacitance; distributed capacitance; DC bus; on-line detection; fault.

Abstract. In view of the influence of grounding capacitance to low frequency signal injection method, a new detection technology is proposed based on DC bus to grounding capacitance. This method does not affect the normal operation of DC power system. The insulation monitoring devices for DC power system is designed. A prototype test that it is able to monitor the capacitance value of the DC bus to grounding capacitance in real time, send out the alarm information with the larger grounding capacitance and improve the reliability of the DC system, which has the advantages of simple operation, accurate measurement and good stability.
\end{abstract}

\section{Introduction}

With the development of electric power industry, the types of power plant and substation are growing longer, and the capacity is growing larger. So, the safe power supply and the safe power generation are important for the whole national economy and people's normal life. DC system is an important part of power plant and substation. The safety and reliability of DC system have affect the safe operation of power plant and substation, and have be relationship to the safe production of entire grid.

With the increase of grid voltage level, the improvement of production, transmission capacity to power plant and substation, and the increase of the complexity of the circuit in the secondary system, DC bus to grounding capacitance is becoming larger and larger imposed on the application of cable and computer protection devices[1]. The misoperation of the protection devices caused by the charge and discharge of the distributed capacitance in DC system has become one of the typical faults in power plant and substation. At present, the commonly using detection method is low frequency signal injection method. Because of the existence of high harmonic and fundamental frequency component belonging to the interference signal in the DC system, when the grounding capacitance is greater than $2 \mathrm{uF}$, the low frequency signal will be submerged, and the value of the grounding resistance and the grounding capacitance will not to be easily measured.

Therefore, this paper presents the detection technology of DC bus to grounding capacitance and designs the insulation monitoring devices for DC power system, which can monitor the value of DC bus to grounding capacitance in real time and send out the alarm information of DC bus to grounding capacitance. The validity and feasibility of the device are verified by the experiments.

\section{The detection principle of bus to grounding capacitance}

The equivalent circuit diagram of DC system is shown in Fig.1. Where, R1 and R2 are the resistors in equalization bridge, $\mathrm{R} 3$ is the resistor in inspection bridge, $\mathrm{S} 1$ is the switch in inspection bridge, $\mathrm{R}+$ and $\mathrm{R}$ - are the resistors of positive and negative electrode to ground, $\mathrm{C}+$ and $\mathrm{C}$ - are the capacitances of positive and negative electrode to ground, and the imaginary frame is the insulation monitoring devices for DC power system. 


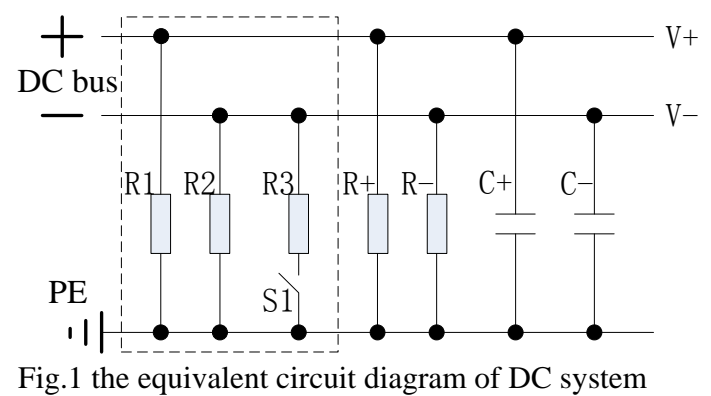

The positive and negative to grounding capacitance contains distributed capacitance in DC system. The distributed capacitance mainly is consisted of two aspects[2][4]. 1) the distributed capacitance of cable line is composed of between electric core and the electric core, between electric core and the shielding layer in the long distance cable, between DC cable and the earth, between the conductive winding of electrical equipment and the metal shell connecting the earth, between phase line and grounding protection line in the cable, between the steel pipe wiring and the steel pipe connecting the earth. 2) the anti interference filter capacitance have been used in relay protection device and automatic device in order to reduce the interference, but the grounding capacitance is introduced into the DC system. The equivalent circuit diagram of DC bus to grounding capacitance is shown in Fig.2.

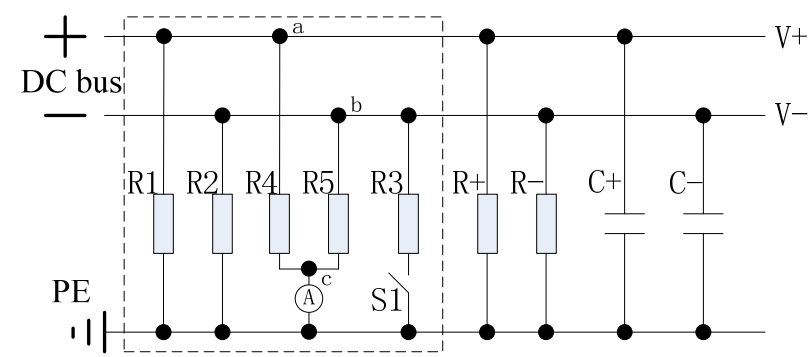

Fig. 2 the equivalent circuit diagram of bus to grounding capacitance

When the DC bus to ground is connected to the capacitance, the capacitance to the DC is open circuit, so the voltage of DC bus to the ground is the voltage of the bridge resistance. In the unbalanced bridge mode, the bus voltage and the current of bus to ground will be changed with the investment of the unbalanced bridge resistor. As the connecting capacitance, the change is growing slowly, the charge and discharge diagram is shown in Fig.3. The value of capacitance is obtained based on coulomb law.

$$
C=\frac{Q}{U}=\frac{\Delta I \times t}{\Delta U}
$$

Where, Delta I and delta $U$ is the variable quantity of current and voltage with switching unbalanced bridge, $t$ is the required time of the change of voltage and current.
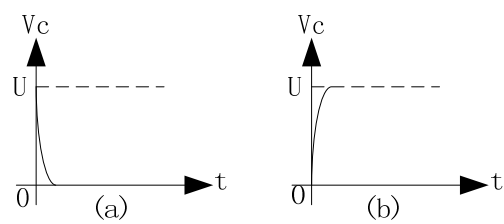

Fig.3 the diagram of the charge and discharge

For a cycle curve is less than $5 \%$, it can be seen that think the capacitance is full. The measuring time is the variable time, so the value of capacitance is obtained by the formula(1).

\section{The design of bus to grounding capacitance}

Hardware design is mainly divided into two parts. The first part is composed of the main control unit and the external device of the main control unit, the other part is composed of the sampling unit, the conditioning unit, the detection control unit, and the alarm control unit based on the DC bus and branch. The hardware block diagram is shown in Fig.4[2][3]. 


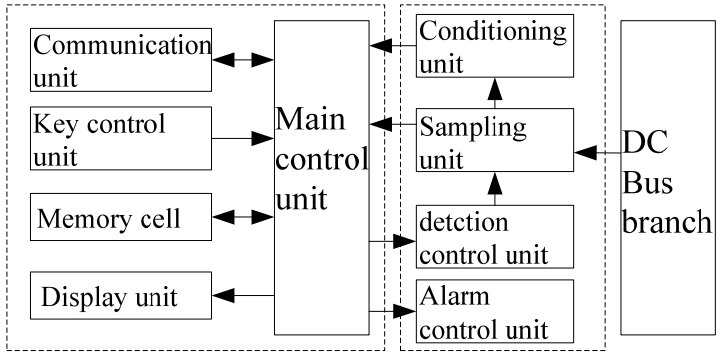

Fig.4 the block diagram of the hardware

The software flow chart is shown in Fig.5. Firstly, the main control unit of the single chip microcomputer can be initialized, and then the voltage of the positive and negative bus to ground is measured by sampling unit and conditioning unit in system normal operation. Secondly, the voltage of $\mathrm{V}+$ and $\mathrm{V}$ - is calculated accurately, at the same time, the current of bus to ground is measured and calculated by the current sampling unit. Subsequently, the value of V+',V-'and I' are calculated respectively, according to a cycle curve is less than 5\%. Lastly, the value of DC bus to grounding capacitance is calculated on the formula (1).

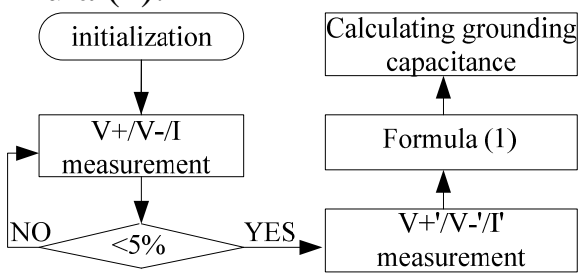

Fig.5 the chart of software

\section{Experiment}

In order to verify the validity and reliability of the detection technology on DC bus to grounding capacitance, the insulation monitoring devices for DC power system is designed. Test instrument is digital oscilloscopeDPO3014. The capacitor is directly connected between the positive and negative bus and the ground, which is shown in Fig.1. The actual measurement of different nominal value of capacitance $(\mathrm{uF})$ is carried out, and the results of measurement are shown in Table 1, the display value of the device is measured (uF).

Table: the experimental data compared nominal value with display value

\begin{tabular}{|c|c|c|c|c|c|c|c|c|c|c|c|c|c|c|c|c|c|}
\hline $\begin{array}{l}\text { Nomial } \\
\text { value }\end{array}$ & 3.3 & $\begin{array}{l}3 . \\
7 \\
\end{array}$ & $\begin{array}{l}4 . \\
4 \\
\end{array}$ & $\begin{array}{l}5 . \\
5\end{array}$ & $\begin{array}{l}7 . \\
3 \\
\end{array}$ & 11 & 22 & 44 & 66 & 88 & 110 & 132 & 154 & 176 & 220 & 242 & 264 \\
\hline $\begin{array}{l}\text { Display } \\
\text { value }\end{array}$ & 3.2 & $\begin{array}{l}3 . \\
7\end{array}$ & $\begin{array}{l}4 . \\
5\end{array}$ & $\begin{array}{l}5 . \\
6\end{array}$ & $\begin{array}{l}7 . \\
4\end{array}$ & $\begin{array}{l}11 \\
.1\end{array}$ & 22 & $\begin{array}{l}43 \\
.2\end{array}$ & $\begin{array}{l}67 \\
.4\end{array}$ & 90.1 & $\begin{array}{l}116 . \\
4\end{array}$ & $\begin{array}{l}140 . \\
2\end{array}$ & $\begin{array}{l}165 . \\
1\end{array}$ & $\begin{array}{l}188 . \\
8\end{array}$ & $\begin{array}{l}237 . \\
6\end{array}$ & $\begin{array}{l}254 . \\
9\end{array}$ & $\begin{array}{l}282 . \\
3\end{array}$ \\
\hline error & 0.1 & 0 & $\begin{array}{l}0 . \\
1\end{array}$ & $\begin{array}{l}0 . \\
1\end{array}$ & $\begin{array}{l}0 . \\
1\end{array}$ & $\begin{array}{l}0 . \\
1\end{array}$ & 0 & $\begin{array}{l}0 . \\
8\end{array}$ & $\begin{array}{l}4 . \\
4\end{array}$ & 2.1 & 6.4 & 8.2 & 11.1 & 12.8 & 17.6 & 12.9 & 18.3 \\
\hline
\end{tabular}

From the data in Table 1, it can be seen that the error between the measured value and the nominal value is less than $5 \%$ in the range of $3 \mathrm{uF} \sim 100 \mathrm{uF}$, and the error between the measured value and the nominal value is less than $10 \%$ in the range of $100 \mathrm{uF} \sim 270 \mathrm{uF}$. There is a certain deviation between the nominal value and the measured value, which is partly due to the deviation between the nominal value and the real value about the capacitor. It can accurately measure the capacitance of bus to ground. At the same time, the capacitance value is more than $100 \mathrm{uF}$, and then, the main control unit of the single chip microcomputer sends out alarm information with large grounding capacitance, the indicator light of bus to grounding capacitance is open. The device displays the capacitance value of the DC bus to grounding capacitance in real time. 


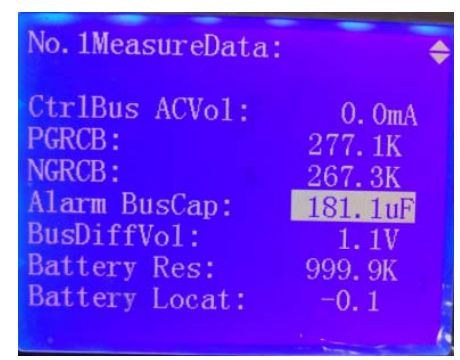

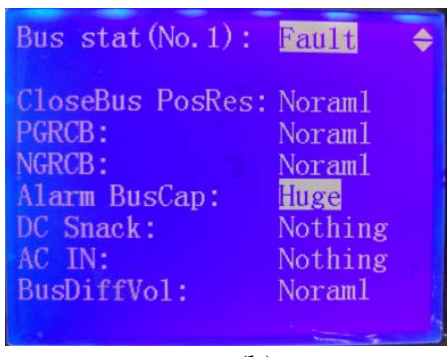

(b)

(a)

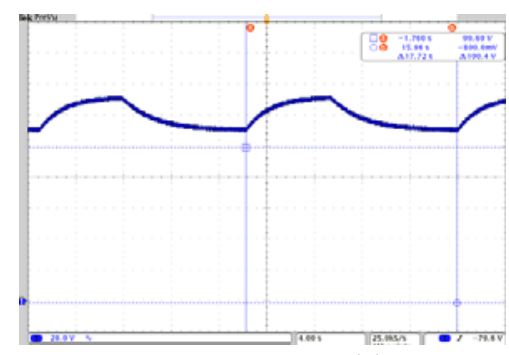

(c)

Fig.6 100VAC of AC injection

The capacitance value of positive bus to grounding capacitance is shown in Fig.6. The display status is given by the display unit of the device, and the conclusion is verified above the paper. The display page of the capacitance value of bus to grounding capacitance is shown in Fig.6(a). The alarm information page of bus to grounding capacitance is shown in Fig.6(b). The charge and discharge curve of bus to grounding capacitance is shown in Fig.6(c). The principle of the capacitance value of positive bus to grounding capacitance is same to the capacitance value of negative bus to grounding capacitance.

\section{Conclusions}

The damage of bus to grounding capacitance is described. The detection method of bus to grounding capacitance is proposed. The insulation monitoring devices for DC power system is designed. The experimental shows that it is able to monitor the capacitance value of the DC bus to grounding capacitance in real time, send out the alarm information with large grounding capacitance. This device has been running for more than half a year in the field of substation, with reliable, accurate, stable and innovative, at the same time, with strong market competitiveness.

\section{Acknowledgements}

This work was financially supported by Science and Technology Project of State Grid Corporation of China(Research on the intelligent on-line monitoring and maintaining technology for AC-DC integration power in substation).

\section{References}

[1] NAN Yin, WANG Xue-nan, FAN Shu-gen, etal. A safety insulation monitoring system which can prevent protective relay misoperation because of one point earthing[J]. Power System Protection and Control, 2014.42(7):134-139

[2] LI Dong-hui, SHI Lin-tong. An overall scheme to detect grounding faults in DC system of power plants and substations[J]. Power System Technology, 2005.29(1):56-59

[3] REN Xian-wen, ZOU Gang, SHI Yong-guang, etal. Research of embedded system based on ARM in DC system grounding fault detection[J].RELAY, 2008.36(2):10-12

[4] WU Jian-ming, YAN Zheng. Influence of control cable distributing capacitance on protection and its countermeasures[J]. Electric Power Automation Equipment, 2007.27(11):115-120 